\title{
Synthesis and Antibacterial Activity of Cinnamaldehyde Acylhydrazone with a 1,4-Benzodioxan Fragment as a Novel Class of Potent $\beta$-Ketoacyl- Acyl Carrier Protein Synthase III (FabH) Inhibitor
}

\author{
Xiaoda Song, ${ }^{a, b, \#}$ Yushun Yang, ${ }^{a, \#}$ Jing Zhao, ${ }^{*, a}$ and Yangjian Chen*,b,c \\ ${ }^{a}$ State Key Laboratory of Pharmaceutical Biotechnology, School of Life Science, Nanjing University; Nanjing 210093, \\ P.R. China: ${ }^{b}$ School of Life Science and Technology, China Pharmaceutical University; Nanjing 210009, P. R. \\ China: and ${ }^{c}$ School of Biology and Pharmaceutics, Zhejiang Pharmaceutical College; Ningbo 315100, P. R. China. \\ Received July 3, 2014; accepted August 18, 2014; advance publication released online September 5, 2014
}

Fatty acid biosynthesis is essential for bacterial survival. $\beta$-Ketoacyl-acyl carrier protein (ACP) synthase III (FabH), is a particularly attractive antibacterial target, since it is central to the initiation of fatty acid biosynthesis. Three series of 21 cinnamaldehyde acylhydrazone derivatives, A3-9, B3-9, and C3-9, were synthesized and evaluated for FabH-inhibitory activity. Compound B6 showed the most potent biological activity against Escherichia coli, Pseudomonas aeruginosa, Staphylococcus aureus, and Bacillus subtilis (minimum inhibitory concentrations (MICs) values: $1.56-3.13 \mu \mathrm{g} / \mathrm{mL}$ ) and was comparable with the positive control. Docking simulation by positioning compound B6 in the FabH structure active site was performed to explore the possible binding model.

Key words cinnamaldehyde; acylhydrazone; benzodioxan; antibacterial; structure-activity relationship; FabH inhibitor

Bactria has become a greater threat to human beings as antibiotic resistance sweeps the world. ${ }^{1)}$ Fatty acid biosynthesis (FAB) is an essential metabolic process for prokaryotic organisms and is required for cell viability and growth. ${ }^{2)}$ The significant differences between human and prokaryotic FAB systems render prokaryotic FAB to be an attractive target. ${ }^{3)}$ The $\beta$-ketoacyl-acyl carrier protein (ACP) synthase III (FabH) has no homologs in human and is one of essential functional enzymes in bacterial FAB system. FabH initiates the FAB cycle by catalyzing the first condensation step between acetylCoA and malonyl-ACP, playing a key regulatory role in the bacterial FAB cycle. ${ }^{4)}$ Many kinds of compounds harbored Schiff base motif or hydrozone motif was screened for antimicrobial activity, some of which are potent inhibitors of $\mathrm{FabH} .{ }^{5}$ For example, compounds 1-8 (Fig. 1A) reported as inhibitors of Escherichia coli FabH showed the most potent FabH inhibitory activity in each article respectively. ${ }^{6-12)}$

1,4-Benzodioxan is an important frame for medicine and widely found in natural products, e.g. silybin, purpurenol, 3,4-dihydroxystyrene dimmers (shown in Fig. 1B). It can also be acquired from more common natural sources. ${ }^{13-17)}$ It was reported that various derivatives of 1,4-benzodioxan show biological activities, ${ }^{18-20)}$ some of which are anticancer agents ${ }^{21)}$ or new anti-inflammatory compounds. ${ }^{18)}$ The aim of this study is to design a series of hydrazide-Schiff bases with a spectrum of antibactrial applications. In view of the findings mentioned above, we report in this present work the synthesis of a series of 1,4-benzodioxan acylhydrazone derivatives (showed in Fig. 1C) to achieve new potential antibacterial FabH inhibitors.

\section{Results and Discussion}

Chemistry In this study, twenty-one cinnamaldehydeacylhydrazone derivatives were designed and synthesized. The synthesis of compounds A3-9; B3-9 and C3-9 fol-

\footnotetext{
The authors declare no conflict of interest.

\# These authors contributed equally to this work.
}

lowed the general pathway outlined in Chart 1. All of them were prepared in three steps, which is based on our previous research. ${ }^{22}$ Esterification of the 2,3-dihydrobenzo[b][1,4]dioxinecarboxylic acid $\mathbf{A}, \mathbf{B}$ and $\mathbf{C}$ with ethanol and thionyl chloride afforded the corresponding ester A1, B1, C1. The hydrazide A2, B2, C2 was obtained by reacting A1, B1, C1 with $85 \%$ hydrazine monohydrate in ethanol. The synthesis of compounds A3-9, B3-9, C3-9 was accomplished by reacting the corresponding hydrazide with different substitued cinnamaldehyde in ethanol. The structure of synthesized compounds A3-9, B3-9, C3-9 was confirmed by spectral data.

Antibacterial Evaluation All the synthesized compounds A3-9, B3-9, C3-9 were evaluated for their antimicrobial activity. Two Gram-negative bacterial strains: Escherichia coli ATCC 25922 and Pseudomonas aeruginosa ATCC 27853 and two Gram-positive bacterial strains: Bacillus subtilis ATCC 6538 and Staphylococcus aureus ATCC 530 were tested with 3-(4,5-dimethylthiazol-2-yl)-2,5-diphenyltetrazolium bromide (MTT) method. The minimum inhibitory concentrations (MICs) of those compounds against these bacteria were presented in Table 1. Kanamycin B was screened under same conditions for comparison. We also took the starting material A, B, C as comparisons. The results reveal that the synthesized compounds exhibit antibacterial activity compared with the starting materials. Among the 21 synthesized compounds, compound B6 displays the most potent activity with MIC values of $1.53,3.13,6.25$ and $6.25 \mu \mathrm{g} / \mathrm{mL}$ against E. coli, $P$. aeruginosa, $S$. aureus and B. subtilis, respectively, which is similar to the positive control, broad-spectrum antibiotic kanamycin B with corresponding MIC values between 1.56 and $3.13 \mu \mathrm{g} / \mathrm{mL}$. C8 $(3.13,6.25,6.25,6.25 \mu \mathrm{g} / \mathrm{mL})$ demonstrated a relatively better activity among $\mathbf{C 3}-\mathbf{C} 9$ and also was comparable with kanamycin B. The A series of compounds show higher MIC values than the series of $\mathbf{B}$ and $\mathbf{C}$ (except compound $\mathbf{A 9}$ ), indicating backbone 2,3-dihydrobenzo[b][1,4]dioxine-2-carboxylic acid decreases the activity (5-carboxylic acid $>6$-carboxylic acid $>2$-carboxylic acid). It may be caused by the fact that 
A.<smiles>Oc1ccc(/C=N/C2CCCCC2)c(O)c1</smiles>

1<smiles>Oc1ccc(C=NNc2ccc(C(F)(F)F)cn2)c(O)c1</smiles>

5

B.<smiles>O=[Se]OC=Cc1ccc2c(c1)OC(c1ccc(O)c(O)c1)C(OS(=O)(=O)[O-])O2</smiles><smiles>Oc1ccc(Br)cc1C=NNc1nc(-c2ccc(Cl)cc2)cs1</smiles>

2<smiles>Oc1ccc(C(=Nc2ccc(Cl)cc2)c2ccc(Cl)cc2)c(Cl)c1</smiles><smiles>O=C(NCCC/N=C/c1cc(Br)ccc1O)c1ccccc1O</smiles>

3<smiles>CCC(=O)N1N=C(c2ccc(OC)cc2)CC1c1ccc(F)cc1</smiles>

7<smiles>Oc1ccc(CCN=Cc2cc(F)ccc2O)cc1</smiles>

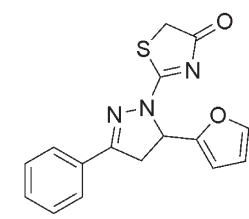

8<smiles>COc1c2c(c3oc(=O)ccc3c1OC)OC(C(C)(C)C)CO2</smiles>

purpurenol

C.

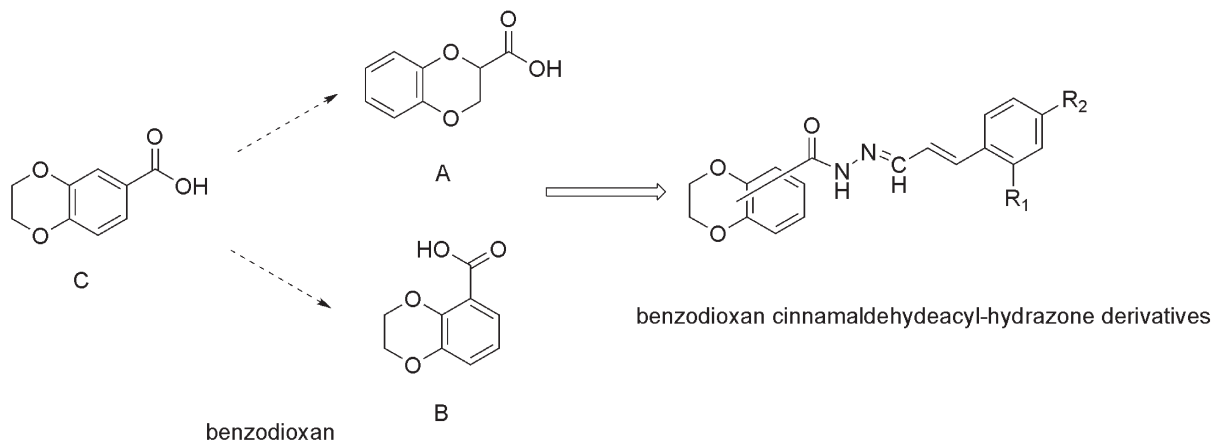

Fig. 1. (A) Some Typical Reported Potential FabH Inhibitors Contained Schiff Base Motif or Hydrozone Motif; (B) Some Natural Products Contained Benzodioxan Motif; (C) The Design of Benzodioxan Cinnamaldehydeacyl-Hydrazone Derivatives

different carboxylic acid substitutions of 2,3-dihydrobenzo[b]$[1,4]$ dioxine orient the compounds differently. Compounds A3, B3, C3 with no substituent in aromatic ring of cinnamaldehyde have little activity with MIC values of $>50 \mu \mathrm{g} /$ $\mathrm{mL}$ against E. coli, P. aeruginosa, S. aureus and B. subtilis, indicating the substituent on aromatic ring of cinnamaldehyde compounds is important.

Subsequently preliminary structure-activity relationship (SAR) studies were conducted to deduce how the structure variation and modification could affect the activity. Within all of the compounds, the $\mathbf{B}$ series shows the more powerful inhibitory activity than the other series. We evaluated the effect of introducing different substitutions on aromatic ring of cinnamaldehyde in B3. Firstly, introducing nitro group on the aromatic ring of cinnamaldehyde in $\mathbf{B 3}$ gives $\mathbf{B 9}$ and $\mathbf{B 6}$ with higher antimicrobial activity. B6 with the nitro group on the ortho-position of aromatic ring of cinnamaldehyde shows MIC values of $1.56-6.25 \mu \mathrm{g} / \mathrm{mL}$, which are better than those of $\mathbf{B 9}$ $(6.25-12.5 \mu \mathrm{g} / \mathrm{mL})$ with the nitro group on the para-position of aromatic ring of cinnamaldehyde. Secondly, compound $\mathbf{B} 7$ bearing the bromine group on the para-position also shows potent activity $(3.13-6.25 \mu \mathrm{g} / \mathrm{mL})$. It has been shown that introducing electron-withdrawing groups (halogen groups or $\mathrm{NO}_{2}$ ) on the aromatic ring of cinnamaldehyde may increase the antimicrobial effects. Thirdly, introducing electron- donating group (methoxy group) on the aromatic ring of cinnamaldehyde in B3 gives B4 and B8 with little antimicrobial activity, indicating that the electron-donating methoxy group does not increase the antimicrobial effects. The $\mathbf{A}$ series (A9 $p-\mathrm{NO}_{2}>\mathbf{A} 7 p-\mathrm{Br}>\mathbf{A} 4 o-\mathrm{F}>\mathbf{A 6} o-\mathrm{NO}_{2}$ ) also shows the introduction of the electron-withdrawing groups (halogen groups or $\mathrm{NO}_{2}$ ) on the aromatic ring of cinnamaldehyde may increase the antimicrobial effects. The $\mathbf{C}$ series is different from $\mathbf{A}$ and B series, given the fact that $\mathbf{C 8} p-\mathrm{OCH}_{3}$ shows the greatest activity of $3.13-6.25 \mu \mathrm{g} / \mathrm{mL}$ and $\mathbf{C 5} o-\mathrm{OCH}_{3}$ has activity in the range of $25-50 \mu \mathrm{g} / \mathrm{mL}$.

Finally, the substituent on aromatic ring of cinnamaldehyde will dramatic contributed antimicrobial activity, and for the series $\mathbf{A}$ and $\mathbf{B}$ the electron-withdrawing groups may increase the antimicrobial effects.

E. coli FabH Inhibitory Activity In addition, we selected the top 7 compounds $\mathbf{B 6}, \mathbf{C 8}, \mathbf{A 9}, \mathbf{B 9}, \mathbf{B 7}, \mathbf{C 6}, \mathbf{C 7}$ and the bottom 3 compounds $\mathbf{B 8}$; A3; $\mathbf{B} 4$ of the antibacterial activity according to their MIC values to test their activity as $E$. coli FabH inhibitors. The results are summarized in Table 2. All the bottom compounds show poor E. coli FabH inhibitory activity and the top compounds display potent $E$. coli FabH inhibitory activity. Among the tested compounds, B6 shows the most potent inhibitory activity with $\mathrm{IC}_{50}$ of $2.5 \mu \mathrm{M}$, which is comparable to the positive control dichloro-1,2-dithiacyclopen- 


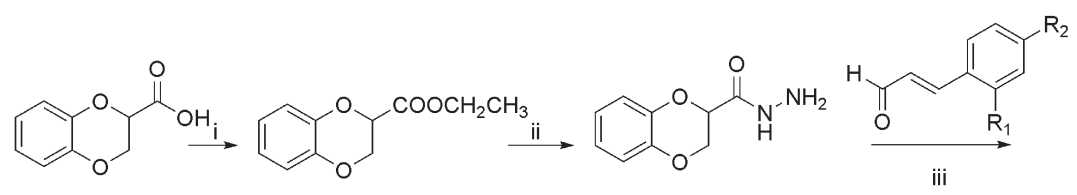

A

A1

A2<smiles>[R9]c1ccc(/C=C/C=N/NC(=O)C2COc3ccccc3O2)c([R])c1</smiles>

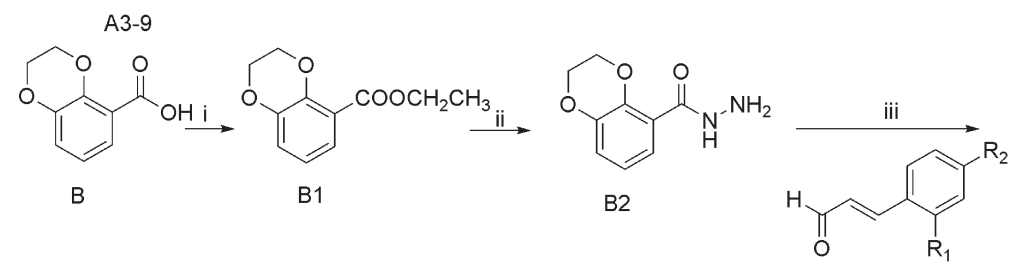<smiles>[R2]c1ccc(/C=C/C=N/NC(=O)c2cccc3c2OCCO3)c([R])c1</smiles>

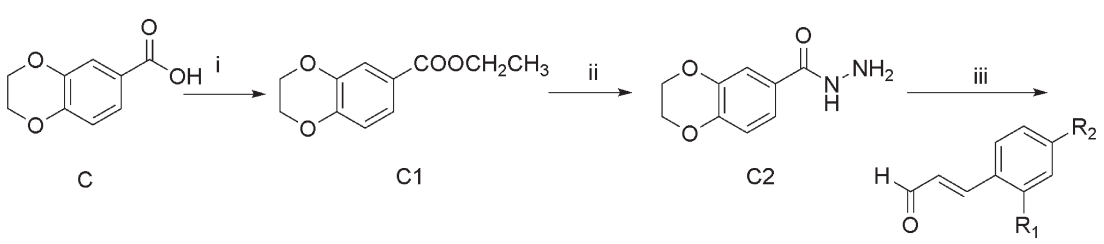<smiles>[R]c1ccc(/C=C/C=N/NC(=O)c2ccc3c(c2)OCCO3)c([R])c1</smiles>

\begin{tabular}{|l|l|l|l|l|l|l|l|l|}
\hline Series $\mathbf{A}$ & $\mathrm{R}_{1}$ & $\mathrm{R}_{2}$ & Series $\mathbf{B}$ & $\mathrm{R}_{1}$ & $\mathrm{R}_{2}$ & Series $\mathbf{C}$ & $\mathrm{R}_{1}$ & $\mathrm{R}_{2}$ \\
\hline $\mathbf{A 3}$ & $\mathrm{H}$ & $\mathrm{H}$ & $\mathbf{B 3}$ & $\mathrm{H}$ & $\mathrm{H}$ & $\mathbf{C 3}$ & $\mathrm{H}$ & $\mathrm{H}$ \\
\hline $\mathbf{A 4}$ & $\mathrm{F}$ & $\mathrm{H}$ & $\mathbf{B 4}$ & $\mathrm{F}$ & $\mathrm{H}$ & $\mathbf{C 4}$ & $\mathrm{F}$ & $\mathrm{H}$ \\
\hline $\mathbf{A 5}$ & $\mathrm{OCH}_{3}$ & $\mathrm{H}$ & $\mathbf{B 5}$ & $\mathrm{OCH}_{3}$ & $\mathrm{H}$ & $\mathbf{C 5}$ & $\mathrm{OCH}_{3}$ & $\mathrm{H}$ \\
\hline $\mathbf{A 6}$ & $\mathrm{NO}_{2}$ & $\mathrm{H}$ & $\mathbf{B 6}$ & $\mathrm{NO}_{2}$ & $\mathrm{H}$ & $\mathbf{C 6}$ & $\mathrm{NO}_{2}$ & $\mathrm{H}$ \\
\hline $\mathbf{A 7}$ & $\mathrm{H}$ & $\mathrm{Br}$ & $\mathbf{B} 7$ & $\mathrm{H}$ & $\mathrm{Br}$ & $\mathbf{C 7}$ & $\mathrm{H}$ & $\mathrm{Br}$ \\
\hline $\mathbf{A 8}$ & $\mathrm{H}$ & $\mathrm{OCH}_{3}$ & $\mathbf{B 8}$ & $\mathrm{H}$ & $\mathrm{OCH}_{3}$ & $\mathbf{C 8}$ & $\mathrm{H}$ & $\mathrm{OCH}_{3}$ \\
\hline A9 & $\mathrm{H}$ & $\mathrm{NO}_{2}$ & $\mathbf{B 9}$ & $\mathrm{H}$ & $\mathrm{NO}_{2}$ & $\mathbf{C 9}$ & $\mathrm{H}$ & $\mathrm{NO}_{2}$ \\
\hline
\end{tabular}

Reagents and conditions: i) EtOH, $\mathrm{SOCl}_{2}$, reflux, overnight; ii) EtOH, $85 \%$ hydrazine hydrate, reflux, overnight; iii) EtOH, $\mathrm{H}_{2} \mathrm{O}$, glacial acetic acid $24 \mathrm{~h}$.

Chart 1. General Synthesis of Compounds (A3-9; B3-9; C3-9)

tenone (DDCP) ${ }^{23)}$ with $\mathrm{IC}_{50}$ of $2.9 \mu \mathrm{M}$. The results indicate that B6 has high binding affinity with E. coli $\mathrm{FabH}$, which supports the observation. Then, analysis between the antibacterial activity against $E$. coli and the $E$. coli FabH inhibitory activity of the top 7 compounds (B6, C8, A9, B9, B7, C6, C7) indicates that there is a moderate correlation $(Y=0.870 X+4.266)$ between FabH inhibition $(Y)$ and inhibition of $E$. coli cellular proliferation $(X)$ with a correlation coefficient of 0.870 and $R$ square value of 0.885 . The compounds selected above were also detected for their hemolytic activity, and all lytic concentration $30 \%\left(\mathrm{LC}_{30}\right)$ were $>10 \mathrm{mg} / \mathrm{mL}$.

Docking Study To gain better understanding on the po- tency of the compounds B6, C8, A9 and guide further SAR studies, we proceeded to examine the interaction of these compounds with molecular docking, which was performed by simulating the 21 compounds with a binding model based on the E. coli $\mathrm{FabH}-\mathrm{CoA}$ complex structure (1HNJ.pdb ${ }^{24)}$ ). The binding modes of potent inhibitor B6, C8, A9 with $1 \mathrm{HNJ}$ are shown in Figs. 2-4, respectively.

In the binding model (Fig. 2), compound $\mathbf{B 6}$ is nicely bound to $1 \mathrm{HNJ}$ via $\pi$-sigma interactions and $\pi$-cation interactions. ARG36 (distance: $5.87 \AA$ ) forms a $\pi$-cation interaction with 5-carboxylic acid, and ALA246 (distance: $2.77 \AA$ ) engenders a $\pi$-sigma interaction with aromatic ring of cinnamaldehyde. 
Table 1. Antibacterial Activity of the Synthesized 1,4-Benzodioxan Derivatives Compounds (A3-A9, B3-B9, C3-C9, A, B, C)

\begin{tabular}{|c|c|c|c|c|}
\hline \multirow{3}{*}{ Compound } & \multicolumn{4}{|c|}{ Minimum inhibitory concentrations $(\mu \mathrm{g} / \mathrm{mL})$} \\
\hline & \multicolumn{2}{|c|}{ Gram-negative } & \multicolumn{2}{|c|}{ Gram-positive } \\
\hline & E. coli & P. aeruginosa & S. aureus & B. subtilis \\
\hline $\mathbf{A 3}$ & 50 & 50 & $>50$ & $>50$ \\
\hline A4 & 25 & 25 & 50 & $>50$ \\
\hline A5 & 25 & 25 & 25 & 25 \\
\hline A6 & 25 & 25 & 50 & 25 \\
\hline A7 & 25 & 25 & 25 & 12.5 \\
\hline A8 & 25 & 12.5 & 12.5 & 12.5 \\
\hline A9 & 3.13 & 3.13 & 6.25 & 6.25 \\
\hline B3 & 50 & 25 & 50 & 50 \\
\hline B4 & $>50$ & $>50$ & $>50$ & $>50$ \\
\hline B5 & 25 & 25 & 25 & 25 \\
\hline B6 & 1.56 & 3.13 & 6.25 & 6.25 \\
\hline B7 & 6.25 & 3.13 & 6.25 & 6.25 \\
\hline B8 & 50 & 50 & 50 & 50 \\
\hline B9 & 6.25 & 6.25 & 12.5 & 6.25 \\
\hline C3 & 50 & 50 & $>50$ & $>50$ \\
\hline $\mathrm{C4}$ & 25 & 25 & 25 & 50 \\
\hline $\mathrm{C} 5$ & 25 & 50 & 25 & 25 \\
\hline C6 & 12.5 & 12.5 & 12.5 & 12.5 \\
\hline C7 & 12.5 & 12.5 & 12.5 & 12.5 \\
\hline C8 & 3.13 & 6.25 & 6.25 & 6.25 \\
\hline C9 & 25 & 12.5 & 25 & 25 \\
\hline $\mathbf{A}$ & $>50$ & $>50$ & $>50$ & $>50$ \\
\hline B & $>50$ & $>50$ & $>50$ & $>50$ \\
\hline C & $>50$ & $>50$ & $>50$ & $>50$ \\
\hline Kanamycin B & 1.56 & 1.56 & 3.13 & 3.13 \\
\hline
\end{tabular}

Table 2. E. coli FabH Inhibitory Activity of the Selected Compounds

\begin{tabular}{ccc}
\hline \hline Compounds & E. coli $\mathrm{FabH} \mathrm{IC}_{50}(\mu \mathrm{M})$ & Hemolysis $\left.\mathrm{LC}_{30}{ }^{a}\right)(\mathrm{mg} / \mathrm{mL})$ \\
\hline B6 & $3.5 \pm 0.31$ & $>10$ \\
C8 & $6.6 \pm 0.52$ & $>10$ \\
A9 & $9.0 \pm 0.13$ & $>10$ \\
B9 & $9.4 \pm 0.28$ & $>10$ \\
B7 & $11.3 \pm 0.47$ & $>10$ \\
C6 & $14.7 \pm 1.09$ & $>10$ \\
C7 & $14.8 \pm 0.43$ & $>10$ \\
B8 & $59.1 \pm 0.71$ & $>10$ \\
A3 & $85.7 \pm 0.92$ & $>10$ \\
B4 & $>100$ & $>10$ \\
DDCP & 2.9 & $>10$ \\
\hline
\end{tabular}

a) Lytic concentration $30 \%$.

It indicates that substituted electron-withdrawing groups enhance the binding between the receptor and the aromatic ring of cinnamaldehyde. As for compound A9 (Fig. 3), 2,3-dihydrobenzo[b][1,4]dioxine-2-carboxylic acid scaffold contributes one hydrogen bond, and $\mathrm{NO}_{2}$ substitution group makes an electronegativity interaction. The hydrogen of guanidyl in ARG36 (distance: 2.6 $\AA$ ) contributes to the hydrogen bonding interaction $\left(\mathrm{O} \ldots \mathrm{H}-\mathrm{N}: 2.37 \AA, 143.280^{\circ}\right)$ with the 4-oxygen atom of $[1,4]$ dioxine-2-carboxylic acid. Furthermore, the $p-\mathrm{NO}_{2}$ aromatic ring of cinnamaldehyde formed an electronegativity interaction with HIS244 (distance: $3.71 \AA$ ), which explains why A9 $\left(p-\mathrm{NO}_{2}\right)$ substitution shows lower
MIC than other substitution group. And C8 (Fig. 4) shows different binding to $1 \mathrm{HNJ}$ compared with $\mathbf{A}$ and $\mathbf{B}$ series. The 2,3-dihydrobenzo[ $[b][1,4]$ dioxine-6-carboxylic acid contributed two hydrogen bonds binding to the receptor. The oxygen atom of dioxine contributes to the hydrogen bonding interaction (O...H-N: $2.41 \AA, 146.198^{\circ}$ ) with the backbone amino hydrogen atom of $\mathrm{ASN} 210\left(\mathrm{O} \ldots \mathrm{H}-\mathrm{N}: 2.01 \AA, 143.280^{\circ}\right)$ with the backbone amino hydrogen atom of GLY209. The steric hindrance of cinnamaldehyde substituted contributes more than electronegativity interaction.

\section{Conclusion}

To conclude, 3 series of compounds, A3-9, B3-9 and C39, have been synthesized and evaluated for their antibacterial activities. Compound B6 displayed the most potent activity against E. coli, P. aeruginosa, S. aureus and B. subtilis, respectively, with MIC values of $1.53,3.13,6.25$ and $6.25 \mu \mathrm{g} /$ $\mathrm{mL}$, being comparable with the positive control. A9, $\mathbf{C 8}$ also displayed potent activity $3.13-6.25 \mu \mathrm{g} / \mathrm{mL}$ correlated with FabH inhibition. These new derivatives demonstrated strong broad-spectrum antimicrobial activity. Docking simulation was performed to position compound B6, $\mathbf{A 9}$ and $\mathbf{C 8}$ into the E. coli $\mathrm{FabH}$ structure active site to determine the probable binding model. It provided further insight into interactions between the enzyme and its ligands. This study shows that cinnamaldehydeacyl-hydrazone with 1,4-benzodioxan fragment are novel compounds that can be potent antimicrobial inhibitor of $\mathrm{FabH}$ and provides valuable information for the design of E. coli $\mathrm{FabH}$ inhibitors as antibacterial agents. 

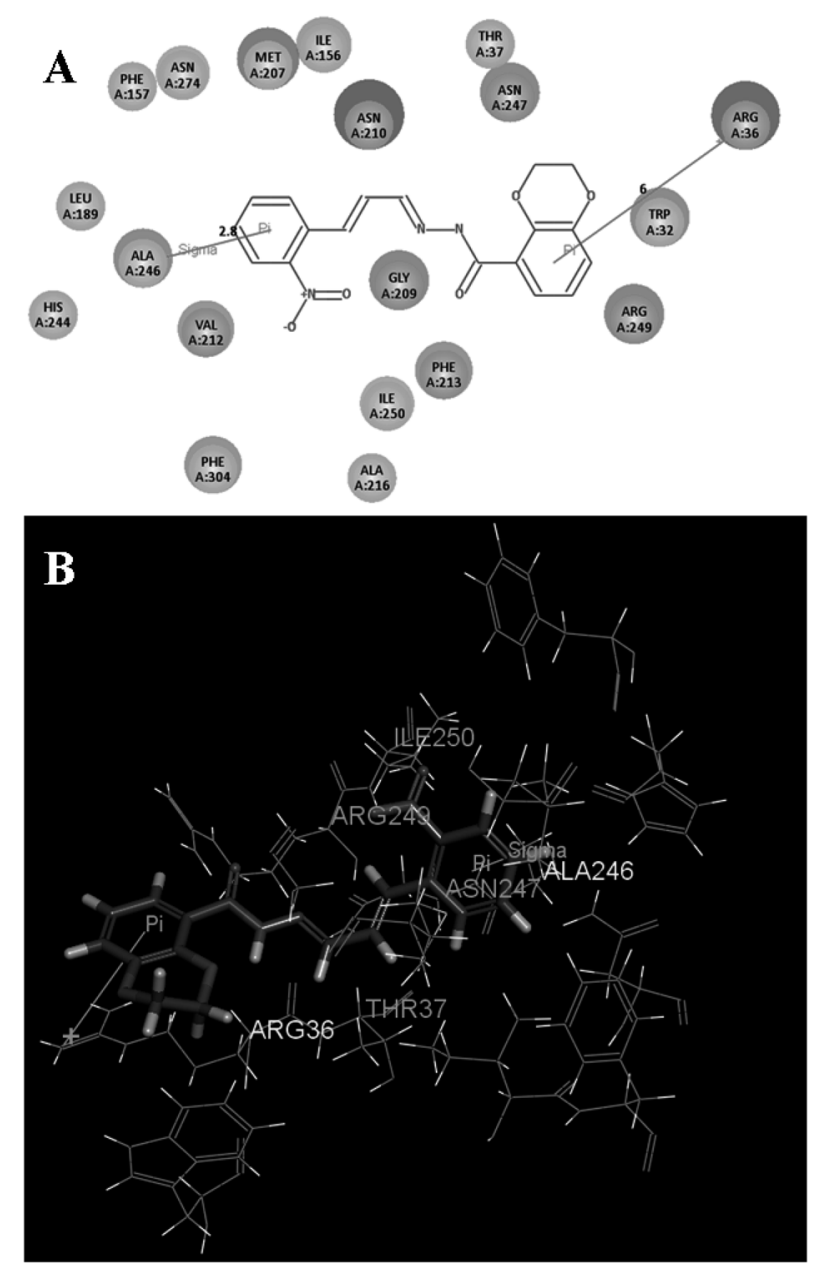

Fig. 2. (A) 2D Molecular Docking Modeling of Compound B6 with $1 \mathrm{HNJ}$; (B) 3D Model of the Interaction between Compound B6 and 1HNJ Bonding Site

The $\pi$-cation interactions and $\pi$-sigma interaction are shown as orange lines with their corresponding amino acids labeled in yellow. (Color images were converted into gray scale.)

\section{Experimental}

Chemistry All chemicals used were purchased from J\&K (China). The elution were monitored using Thin layer chromatography (TLC). TLC was run on the silica gel coated aluminum sheets (Silica Gel $60 \AA$ GF254, E. Merck, Germany) and visualized in UV light $(254 \mathrm{~nm})$. Separation of the compounds by column chromatography was carried out with silica gel 60 (200-300 mesh ASTM, E. Merck, Germany). Developed plates were visualized by Spectroline ENF 260C/F UV apparatus. The quantity of silica gel used was 50-100 times the weight charged on the column. Melting points (uncorrected) were determined on a XT4MP apparatus (Taike Corp., Beijing, China). Electrospray ionization (ESI) mass spectra were obtained on a Mariner System 5304 mass spectrometer, and ${ }^{1} \mathrm{H}-\mathrm{NMR}$ spectra were recorded on a DPX300 spectrometer at $25^{\circ} \mathrm{C}$ with TMS and solvent signals allotted as internal standards. Chemical shifts are reported in ppm $(\delta)$. Elemental analyses were performed on a CHN-O-Rapid instrument and were within $0.4 \%$ of the theoretical values.

General Method of Synthesis of Ethyl 2,3-Dihydrobenzo[b][1,4]dioxinecarboxylate (A1, B1 and C1) 2,3-Dihydrobenzo[b]$[1,4]$ dioxinecarboxylic acid $\mathbf{A}, \mathbf{B}$ and $\mathbf{C}(10 \mathrm{mmol})$ in ethanol $(200 \mathrm{~mL})$ was treated with thionyl chloride $(5 \mathrm{~mL})$ under reflux
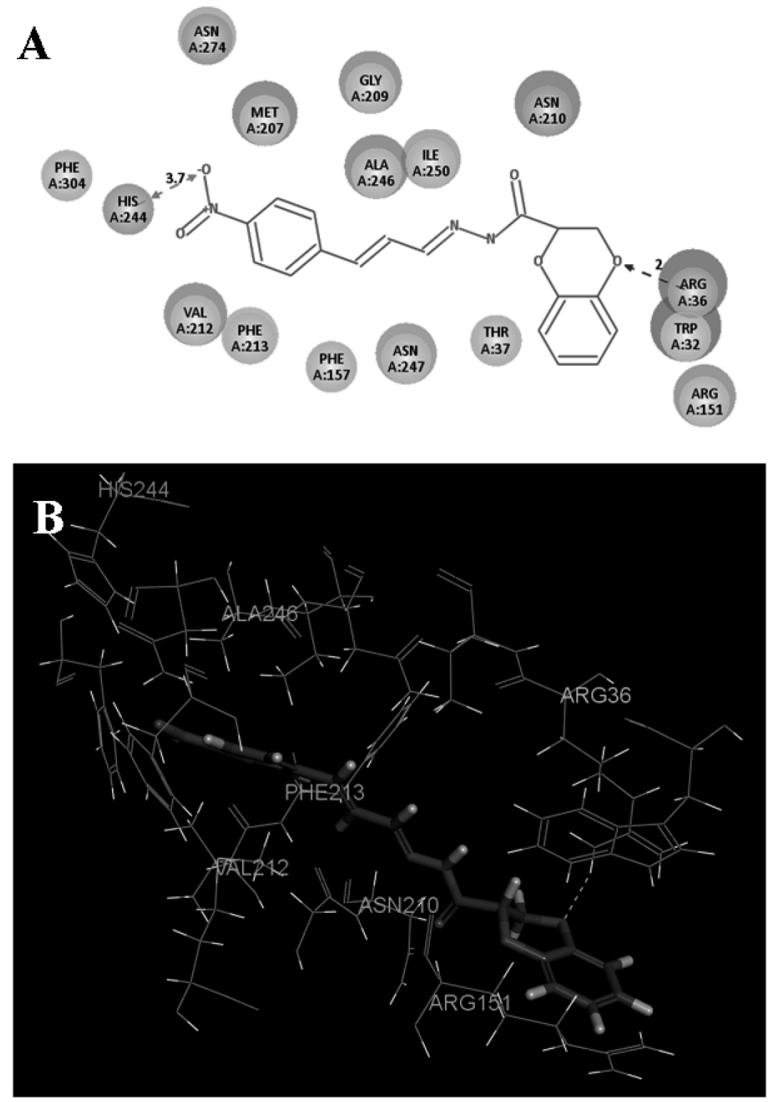

Fig. 3. (A) 2D Molecular Docking Modeling of Compound A9 with $1 \mathrm{HNJ}$; (B) 3D Model of the Interaction between Compound $\mathbf{A 9}$ and $1 \mathrm{HNJ}$ Bonding Site

The one H-bond (green line) is displayed as dotted lines and the amino acid it acts on is labeled in green. (Color images were converted into gray scale.)

overnight. Excess ethanol was distilled out and the solid left was dissovled in ethyl acetate $(150 \mathrm{~mL})$, washed with saturation sodium bicarbonate $(200 \mathrm{~mL})$ and then sodium chloride $(200 \mathrm{~mL})$. After drying the organic layer with anhydrous $\mathrm{Na}_{2} \mathrm{SO}_{4}$ and evaporating the solvent under reduced pressure and solid appeared. The solid was recrystallized from ethanol to obtain the compound A1, B1 and $\mathbf{C 1}$. The completion of the reaction was monitored on TLC by using silica gel-G coated plates by using ethyl acetate and petroleum ether $(1: 1)$ as the elution and observed in UV light.

General Method of Synthesis of Ethyl 2,3-Dihydrobenzo[b] $[1,4]$ dioxinecarbohydrazide (A2, B2 and C2) A stirred solution of compound A1, B1 and $\mathbf{C 1}(5 \mathrm{mmol})$ in ethanol $(200 \mathrm{~mL})$ was treated with the hydrazine hydrate $(85 \%)$, under refluxed overnight. Excessive ethanol was distilled out and the contents were allowed to cool. The crystals formed was filtered, washed thoroughly with water and dried to obtain the compound A2, B2 and C2.

General Procedure for Synthesis of the Target Compounds To dissolve hydrazide A2, B2 and C2 (1 mmol) and Cinnamaldehydes $(1 \mathrm{mmol})$ in ethanol $(15 \mathrm{~mL})$, water $(1 \mathrm{~mL})$ was added followed by dropwise addition of glacial acetic acid $(0.2 \mathrm{~mL})$. The resulting mixture was stirred at room temperature until the target product precipitated from the solvent, which was collected using suction filtration and dried, followed by recrystallization in ethanol.

$(E)-N^{\prime}-((E)-3$-Phenylallylidene)-2,3-dihydrobenzo $[b][1,4]-$ 


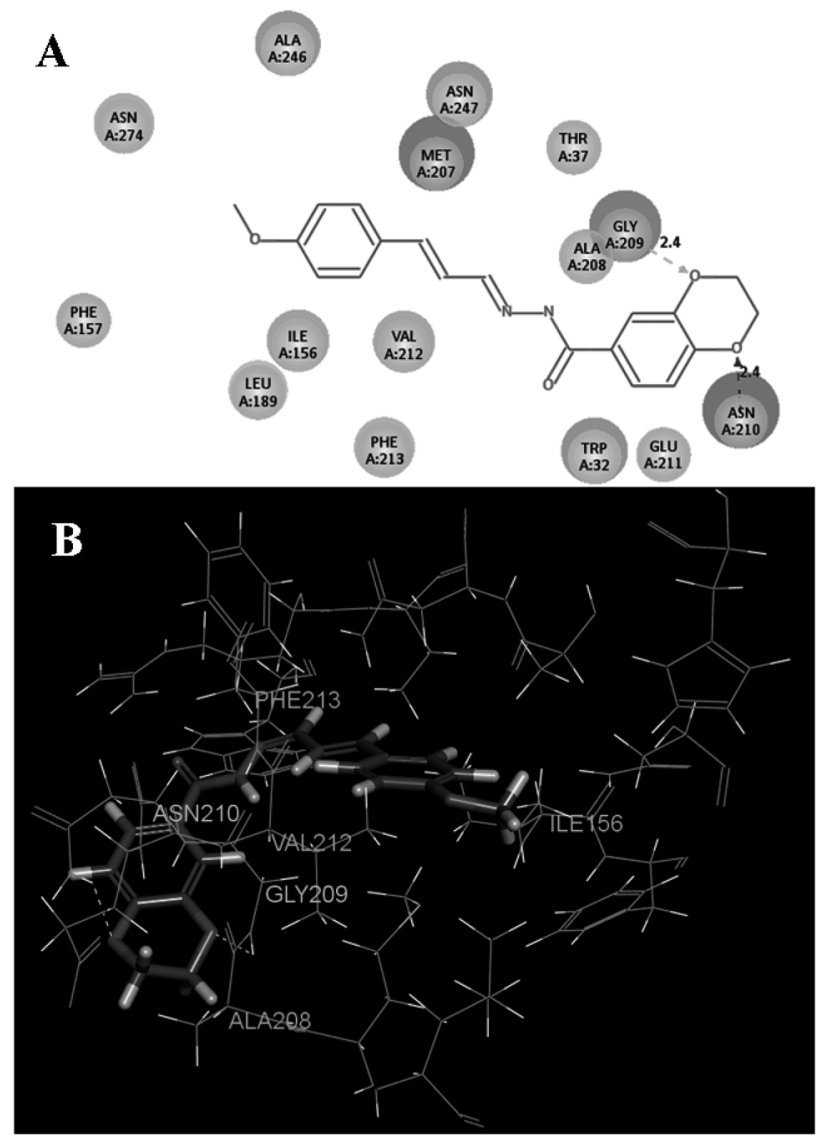

Fig. 4. (A) 2D Molecular Docking Modeling of Compound C8 with $1 \mathrm{HNJ}$; (B) 3D Model of the Interaction between Compound C8 and $1 \mathrm{HNJ}$ Bonding Site

The two H-bonds (green line) are displayed as dotted lines and the amino acid it acts on is labeled in green. (Color images were converted into gray scale.)

dioxine-2-carbohydrazide (A3) Light yellow powder, yield $73 \%$; mp $169-171^{\circ} \mathrm{C} .{ }^{1} \mathrm{H}-\mathrm{NMR}\left(300 \mathrm{MHz}, \mathrm{DMSO}-d_{6}\right) \delta: 4.47$ $(1 \mathrm{H}, \mathrm{s}), 4.73(1 \mathrm{H}, \mathrm{s}), 5.01(1 \mathrm{H}, \mathrm{s}), 6.86(1 \mathrm{H}, \mathrm{s}), 6.92-6.98(4 \mathrm{H}$, m), 7.23-7.26 (1H, m), 7.33-7.40 (3H, m), 7.58-7.63 (3H, m), $10.63(1 \mathrm{H}, \mathrm{s}) .{ }^{13} \mathrm{C}-\mathrm{NMR}\left(75 \mathrm{MHz}, \mathrm{DMSO}-d_{6}\right) \delta: 64.2(\mathrm{t}), 70.1$ (d), 117.5 (d), 117.9 (d), 120.5 (d), 122.4 (d), 127.4 (d), 128.1 (d), 128.9 (d), 129.1 (d), 137.1 (d), 144.0 (d), 146.2 (d), 151.5 (d), 165.9 (s). ESI-MS m/z: $\left.309.1\left(\mathrm{C}_{18} \mathrm{H}_{16} \mathrm{~N}_{2} \mathrm{O}_{3} \text {, [M+H] }\right]^{+}\right)$. Anal. Calcd for $\mathrm{C}_{18} \mathrm{H}_{16} \mathrm{~N}_{2} \mathrm{O}_{3}$ : C, 70.12; H, 5.23; N, 9.09; Found: C, 70.17; H, 5.25; N, 9.12\%.

(E) - $N^{\prime}$ - ((E)-3 - (2 - Fluorophenyl) allylidene) - 2, 3 dihydrobenzo $[b][1,4]$ dioxine-2-carbohydrazide (A4) Light yellow powder, yield 76\%; mp $171-173^{\circ} \mathrm{C}$. ${ }^{1} \mathrm{H}-\mathrm{NMR}$ $\left(300 \mathrm{MHz}, \mathrm{DMSO}-d_{6}\right) \delta: 4.48(1 \mathrm{H}, \mathrm{s}), 4.72(1 \mathrm{H}, \mathrm{s}), 5.00(1 \mathrm{H}, \mathrm{s})$, $6.70(1 \mathrm{H}, \mathrm{s}), 6.88-6.92(4 \mathrm{H}, \mathrm{m}), 7.10-7.15(3 \mathrm{H}, \mathrm{m}), 7.34(1 \mathrm{H}, \mathrm{d}$, $J=5.74), 7.52(1 \mathrm{H}, \mathrm{d}, J=4.47), 7.62-7.66(1 \mathrm{H}, \mathrm{m}), 10.57(1 \mathrm{H}, \mathrm{s})$. ${ }^{13} \mathrm{C}-\mathrm{NMR}\left(75 \mathrm{MHz}, \mathrm{DMSO}-d_{6}\right) \delta: 64.3(\mathrm{t}), 70.2(\mathrm{~d}), 115.6(\mathrm{~d}$, $J=20.1$ C20-F coupling) 117.4 (d), 117.9 (d), 120.5 (d), 122.3 (d), 122.6 (d, $J=7.6$ C17-F coupling), 124.6 (d, $J=21.3 \mathrm{C} 18-\mathrm{F}$ coupling), 125.3 (d), 126.6 (d), 128.3 (d), 129.0 (d, $J=7.2$ C21-F coupling), 144.0 (d), 146.1 (d), 151.1 (d), 162.1 (d, $J=251.2$ C19-F coupling), 167.1 (s). ESI-MS m/z: $327.1 \quad\left(\mathrm{C}_{18} \mathrm{H}_{15} \mathrm{FN}_{2} \mathrm{O}_{3}\right.$, $[\mathrm{M}+\mathrm{H}]^{+}$). Anal. Calcd for $\mathrm{C}_{18} \mathrm{H}_{15} \mathrm{FN}_{2} \mathrm{O}_{3}: \mathrm{C}, 66.25 ; \mathrm{H}, 4.63 ; \mathrm{N}$, 8.58; Found: C, 66.21; H, 4.59; N, 8.62\%.

$(E)-N^{\prime}-((E)-3$ - (2 -Methoxy phenyl)allylidene $)-2,3$ dihydrobenzo $[b][1,4]$ dioxine-2-carbohydrazide (A5) Light yellow powder, yield $78 \%$; mp $172-174^{\circ} \mathrm{C} . \quad{ }^{1} \mathrm{H}-\mathrm{NMR}$ $\left(300 \mathrm{MHz}, \mathrm{DMSO}-d_{6}\right) \delta: 3.76(3 \mathrm{H}, \mathrm{s}), 4.46(1 \mathrm{H}, \mathrm{s}), 4.77(1 \mathrm{H}, \mathrm{s})$, $5.10(1 \mathrm{H}, \mathrm{s}), 6.68-6.70(1 \mathrm{H}, \mathrm{m}), 6.90-7.02(7 \mathrm{H}, \mathrm{m}), 7.22(1 \mathrm{H}, \mathrm{t}$, $J=7.68 \mathrm{~Hz}), 7.55(1 \mathrm{H}, \mathrm{d}, J=5.09 \mathrm{~Hz}),, 7.68(1 \mathrm{H}, \mathrm{d}, J=4.31 \mathrm{~Hz}$, , $10.35(1 \mathrm{H}, \mathrm{s}) .{ }^{13} \mathrm{C}-\mathrm{NMR}\left(75 \mathrm{MHz}, \mathrm{DMSO}-d_{6}\right) \delta: 57.1(\mathrm{q}), 64.3$ (t), 71.0 (d), 113.1 (d), 117.4 (d), 117.9 (d), 120.5 (d), 121.2 (d), 122.2 (d), 127.5 (d), 128.4 (d), 130.1 (d), 132.9 (d), 144.0 (d), 146.8 (d), 151.5 (d), 157.1 (d), 165.9 (s). ESI-MS $m / z: 339.2$ $\left(\mathrm{C}_{19} \mathrm{H}_{18} \mathrm{~N}_{2} \mathrm{O}_{4},[\mathrm{M}+\mathrm{H}]^{+}\right)$. Anal. Calcd for $\mathrm{C}_{19} \mathrm{H}_{18} \mathrm{~N}_{2} \mathrm{O}_{4}$ : C, 67.44; H, 5.36; N, 8.28; Found: C, 67.42; H, 5.31; N, 8.30\%.

$(E)-N^{\prime}-((E)-3$ - (2 - Nit rophenyl)allylidene $)-2,3$ dihydrobenzo $[b][1,4]$ dioxine-2-carbohydrazide (A6) Yellow powder, yield $53 \%$; mp $185-187^{\circ} \mathrm{C}$. ${ }^{1} \mathrm{H}-\mathrm{NMR}(300 \mathrm{MHz}$, DMSO- $\left.d_{6}\right) \delta: 4.36(1 \mathrm{H}, \mathrm{s}), 4.43(1 \mathrm{H}, \mathrm{s}), 4.99(1 \mathrm{H}, \mathrm{s}), 6.82-6.90$ $(5 \mathrm{H}, \mathrm{m}), 7.35(1 \mathrm{H}, \mathrm{d}, J=4.37), 7.53(1 \mathrm{H}, \mathrm{d}, J=5.12), 7.81-7.94$ (2H, m), 8.15-8.21 (2H, m), $10.58(1 \mathrm{H}, \mathrm{s}) .{ }^{13} \mathrm{C}-\mathrm{NMR}(75 \mathrm{MHz}$, DMSO-d D $_{6} \delta: 64.3$ (t), 70.9 (d), 117.4 (d), 117.9 (d), 120.5 (d), 122.1 (d), 126.4 (d), 126.9 (d), 128.7 (d), 130.4 (d), 131.1 (d), 131.6 (d), 132.9 (d), 144.0 (d), 146.8 (d), 147.0 (d), 151.5 (d), 166.2 (s). ESI-MS m/z: $354.1\left(\mathrm{C}_{18} \mathrm{H}_{15} \mathrm{~N}_{3} \mathrm{O}_{5},[\mathrm{M}+\mathrm{H}]^{+}\right)$. Anal. Calcd for $\mathrm{C}_{18} \mathrm{H}_{15} \mathrm{~N}_{3} \mathrm{O}_{5}$ : C, 61.19; H, 4.28; N, 11.89; Found: C, 61.21; H, 4.18; N, 12.16\%.

$(E)-N^{\prime}-((E)-3$ - (4 - B romophenyl)allylidene) - 2,3 dihydrobenzo $[b][1,4]$ dioxine-2-carbohydrazide (A7) Brown powder, yield 75\%; mp $201-203^{\circ} \mathrm{C} .{ }^{1} \mathrm{H}-\mathrm{NMR}$ $\left(300 \mathrm{MHz}, \mathrm{DMSO}-d_{6}\right) \delta: 4.32(1 \mathrm{H}, \mathrm{s}), 4.61(1 \mathrm{H}, \mathrm{s}), 4.91(1 \mathrm{H}, \mathrm{s})$, 6.94-7.06 (5H, m), $7.21(1 \mathrm{H}, \mathrm{d}, J=2.58 \mathrm{~Hz}), 7.56-7.65(5 \mathrm{H}, \mathrm{m})$, $10.79(1 \mathrm{H}, \mathrm{s}) .{ }^{13} \mathrm{C}-\mathrm{NMR}\left(75 \mathrm{MHz}, \mathrm{DMSO}-d_{6}\right) \delta: 64.2(\mathrm{t}), 70.1$ (d), 117.5 (d), 117.9 (d), 120.5 (d), 122.4 (d), 123.1 (d), 128.1 (d), 128.9 (d), 129.1 (d), 131.5 (d), 137.5 (d), 144.0 (d), 146.2 (d), 151.5 (d), 165.9 (s). ESI-MS m/z: $387.0 \quad\left(\mathrm{C}_{18} \mathrm{H}_{15} \mathrm{BrN}_{2} \mathrm{O}_{3}\right.$, $\left.[\mathrm{M}+\mathrm{H}]^{+}\right) ; 389.0\left([\mathrm{M}+2+\mathrm{H}]^{+}\right)$. Anal. Calcd for $\mathrm{C}_{18} \mathrm{H}_{15} \mathrm{BrN}_{2} \mathrm{O}_{3}$ : C, 55.83; H, 3.90; N, 7.23; Found: C, 55.82; H, 3.93; N, 7.21\%.

$(E)-N^{\prime}-((E)-3-(4-M e t h o x y$ phenyl)allylidene $)-2,3$ dihydrobenzo $[b][1,4]$ dioxine-2-carbohydrazide (A8) Light yellow powder, yield $88 \%$; mp $169-171^{\circ} \mathrm{C}$. ${ }^{1} \mathrm{H}-\mathrm{NMR}$ $\left(300 \mathrm{MHz}, \mathrm{DMSO}-d_{6}\right) \delta$ : $3.92(3 \mathrm{H}, \mathrm{s}), 4.27-4.33(1 \mathrm{H}, \mathrm{m})$, 4.57-4.62 (1H, m), 4.87-4.90 (1H, m), 6.89-6.96 (7H, m), $7.32(1 \mathrm{H}, \mathrm{d}, J=2.37 \mathrm{~Hz}), 7.38-7.42(1 \mathrm{H}, \mathrm{m}), 7.61-7.65(2 \mathrm{H}, \mathrm{m})$, $10.80(1 \mathrm{H}, \mathrm{s}) .{ }^{13} \mathrm{C}-\mathrm{NMR}\left(75 \mathrm{MHz}, \mathrm{DMSO}-d_{6}\right) \delta: 56.4(\mathrm{q}), 64.4$ (t), 71.0 (d), 114.4 (d), 117.6 (d), 117.9 (d), 120.5 (d), 122.1 (d), 128.1 (d), 128.8 (d), 129.6 (d), 130.3 (d), 144.0 (d), 146.2 (d), 151.5 (d), 160.4 (d), 165.9 (s). ESI-MS m/z: $339.1\left(\mathrm{C}_{19} \mathrm{H}_{18} \mathrm{~N}_{2} \mathrm{O}_{4}\right.$, $\left.[\mathrm{M}+\mathrm{H}]^{+}\right)$. Anal. Calcd for $\mathrm{C}_{19} \mathrm{H}_{18} \mathrm{~N}_{2} \mathrm{O}_{4}: \mathrm{C}, 67.44 ; \mathrm{H}, 5.36 ; \mathrm{N}$, 8.28; Found: C, 67.42; H, 5.36; N, 8.32\%.

$(E)-N^{\prime}-((E)-3$ - (4 - Nitrophenyl)allylidene $)-2,3$ dihydrobenzo $[b][1,4]$ dioxine-2-carbohydrazide (A9) Brown powder, yield 70\%; mp $189-191{ }^{\circ} \mathrm{C} .{ }^{1} \mathrm{H}-\mathrm{NMR}$ $\left(300 \mathrm{MHz}, \mathrm{DMSO}-d_{6}\right) \delta: 4.43(2 \mathrm{H}, \mathrm{s}), 5.06(1 \mathrm{H}, \mathrm{s}), 6.85-6.89$ $(3 \mathrm{H}, \mathrm{m}), 6.91-7.04(1 \mathrm{H}, \mathrm{m}), 7.14(1 \mathrm{H}, \mathrm{d}, J=3.72 \mathrm{~Hz}), 7.35-7.45$ $(2 \mathrm{H}, \mathrm{m}), 8.10(2 \mathrm{H}, \mathrm{d}, J=2.40 \mathrm{~Hz}), 8.30(2 \mathrm{H}, \mathrm{d}, J=2.43 \mathrm{~Hz})$, $10.49(1 \mathrm{H}, \mathrm{s}) .{ }^{13} \mathrm{C}-\mathrm{NMR}\left(75 \mathrm{MHz}, \mathrm{DMSO}-d_{6}\right) \delta: 64.3$ (t), 71.0 (d), 117.5 (d), 117.9 (d), 120.6 (d), 122.2 (d), 124.4 (d), 128.1 (d), 128.3 (d), 128.8 (d), 144.1 (d), 146.2 (d), 147.3 (d), 151.5 (d), 166.1 (s). ESI-MS m/z: $354.2\left(\mathrm{C}_{18} \mathrm{H}_{15} \mathrm{~N}_{3} \mathrm{O}_{5},[\mathrm{M}+\mathrm{H}]^{+}\right)$. Anal. Calcd for $\mathrm{C}_{18} \mathrm{H}_{15} \mathrm{~N}_{3} \mathrm{O}_{5}$ : C, 61.19; H, 4.28; N, 11.89; Found: C, $61.20 ; \mathrm{H}, 4.30 ; \mathrm{N}, 11.85 \%$.

(E)- $N^{\prime}-((E)-3$-Phenylallylidene)-2,3-dihydrobenzo $[b][1,4]-$ dioxine-5-carbohydrazide (B3) Light yellow powder, yield $71 \%$; mp $145-147^{\circ} \mathrm{C}$. ${ }^{1} \mathrm{H}-\mathrm{NMR}\left(300 \mathrm{MHz}, \mathrm{DMSO}-d_{6}\right) \delta: 4.54$ $(4 \mathrm{H}, \mathrm{s}), 6.93(1 \mathrm{H}, \mathrm{t}, J=7.50 \mathrm{~Hz}), 7.00-7.11(2 \mathrm{H}, \mathrm{m}), 7.33-7.40$ 
(4H, m), 7.48-7.51 (2H, m), 7.63-7.87 (2H, m), $10.55(1 \mathrm{H}, \mathrm{s})$. ${ }^{13} \mathrm{C}-\mathrm{NMR}\left(75 \mathrm{MHz}, \mathrm{DMSO}-d_{6}\right) \delta$ : $61.6(\mathrm{t}), 63.3(\mathrm{t}), 119.7(\mathrm{~d})$, 121.0 (d), 122.4 (d), 122.7 (d), 127.4 (d), 128.1 (d), 128.8 (d), 137.1 (d), 144.4 (d), 150.1 (d), 150.8 (d), 151.5 (d), 163.5 (s). ESI-MS m/z: $309.1\left(\mathrm{C}_{18} \mathrm{H}_{16} \mathrm{~N}_{2} \mathrm{O}_{3},[\mathrm{M}+\mathrm{H}]^{+}\right)$. Anal. Calcd for $\mathrm{C}_{18} \mathrm{H}_{16} \mathrm{~N}_{2} \mathrm{O}_{3}$ : C, 70.12; H, 5.23; N, 9.09; Found: C, 70.10; H, $5.27 ; \mathrm{N}, 9.10 \%$.

(E) - $N^{\prime}-((E)-3$ - (2 - Fluorophenyl)allylidene) $-2,3$ dihydrobenzo $[b][1,4]$ dioxine-5-carbohydrazide (B4) Light yellow powder, yield $74 \%$; mp $143-145^{\circ} \mathrm{C} .{ }^{1} \mathrm{H}-\mathrm{NMR}(300 \mathrm{MHz}$, DMSO- $\left.d_{6}\right) \delta: 4.35$ (4H, s), 6.78-6.95 (2H, m), 7.15-7.20 $(3 \mathrm{H}, \mathrm{m}), 7.35-7.40(2 \mathrm{H}, \mathrm{m}), 7.53-7.65(3 \mathrm{H}, \mathrm{m}), 10.89(1 \mathrm{H}, \mathrm{s})$. ${ }^{13} \mathrm{C}-\mathrm{NMR}\left(75 \mathrm{MHz}, \mathrm{DMSO}-d_{6}\right) \delta: 61.5(\mathrm{t}), 63.3$ (t), 70.2 (d), 115.6 (d, $J=20.2$ C20-F coupling), 119.3 (d), 121.1 (d), 122.4, 122.8 (d), 124.7 (d, J=21.1 C18-F coupling), 125.4 (d), 126.5 (d), 128.3 (d, J=8.6 C23-F coupling), 129.0 (d, $J=7.6$ C21-F coupling), 141.5 (d), 149.9 (d), 151.1 (d), 162.1 (d, $J=251.8$ C19-F coupling), 163.6 (s). ESI-MS m/z: $327.1 \quad\left(\mathrm{C}_{18} \mathrm{H}_{15} \mathrm{FN}_{2} \mathrm{O}_{3}\right.$, $\left.[\mathrm{M}+\mathrm{H}]^{+}\right)$. Anal. Calcd for $\mathrm{C}_{18} \mathrm{H}_{15} \mathrm{FN}_{2} \mathrm{O}_{3}: \mathrm{C}, 66.25 ; \mathrm{H}, 4.63 ; \mathrm{F}$, 5.82; N, 8.58. Found: C, 66.27; H, 5.90; N, 8.60\%.

(E)- $N^{\prime}$ - ((E)-3 - (2 -Methoxy phenyl)allylidene)-2,3 dihydrobenzo $[b][1,4]$ dioxine-5-carbohydrazide (B5) Light yellow powder, yield $71 \%$; mp $169-171{ }^{\circ} \mathrm{C} .{ }^{1} \mathrm{H}-\mathrm{NMR}(300 \mathrm{MHz}$, DMSO-d $d_{6} \delta: 3.81(3 \mathrm{H}, \mathrm{s}), 4.35(4 \mathrm{H}, \mathrm{s}), 6.78-7.05(5 \mathrm{H}, \mathrm{m})$, $7.36-7.43(3 \mathrm{H}, \mathrm{m}), 7.55(1 \mathrm{H}, \mathrm{d}, J=4.56 \mathrm{~Hz}), 7.67(1 \mathrm{H}, \mathrm{d}$, $J=4.03 \mathrm{~Hz}), 10.80(1 \mathrm{H}, \mathrm{s}) .{ }^{13} \mathrm{C}-\mathrm{NMR}\left(75 \mathrm{MHz}, \mathrm{DMSO}-d_{6}\right) \delta$ : 57.1 (q), 61.5 (t), 63.3 (t), 113.0 (d), 119.7 (d), 121.0 (d), 121.3 (d), 122.4 (d), 122.7 (d), 127.4 (d), 128.4 (d), 130.1 (d), 132.9 (d), 141.3 (d), 149.5 (d), 150.9 (d), 157.5 (d), 163.6 (s). ESI-MS m/z: $339.2\left(\mathrm{C}_{19} \mathrm{H}_{18} \mathrm{~N}_{2} \mathrm{O}_{4},[\mathrm{M}+\mathrm{H}]^{+}\right)$. Anal. Calcd for $\mathrm{C}_{19} \mathrm{H}_{18} \mathrm{~N}_{2} \mathrm{O}_{4}$ : C, 67.44; H, 5.36; N, 8.28 Found: C, 67.49; H, 5.22; N, 8.40\%.

(E) - $N^{\prime}-((E)-3$ - (2 - Nit rophenyl)allylidene $)-2,3$ dihydrobenzo $[b][1,4]$ dioxine-5-carbohydrazide (B6) Brown powder, yield 57\%; mp $189-191{ }^{\circ} \mathrm{C}$. ${ }^{1} \mathrm{H}-\mathrm{NMR}$ $\left(300 \mathrm{MHz}, \mathrm{DMSO}-d_{6}\right) \delta: 4.37(4 \mathrm{H}, \mathrm{s}), 6.75(1 \mathrm{H}, \mathrm{d}, J=2.73 \mathrm{~Hz})$, $7.20(1 \mathrm{H}, \mathrm{d}, J=3.42 \mathrm{~Hz}), 7.35-7.50(4 \mathrm{H}, \mathrm{m}), 7.80-7.86(2 \mathrm{H}, \mathrm{m})$, 8.13-8.21 (2H, m), $10.55(1 \mathrm{H}, \mathrm{s}) .{ }^{13} \mathrm{C}-\mathrm{NMR}(75 \mathrm{MHz}, \mathrm{DMSO}-$ $\left.d_{6}\right) \delta: 61.6(\mathrm{t}), 63.3(\mathrm{t}), 119.6(\mathrm{~d}), 121.1(\mathrm{~d}), 122.4(\mathrm{~d}), 122.8(\mathrm{~d})$, 126.5 (d), 126.9 (d), 128.4 (d), 130.5 (d), 131.1 (d), 131.5 (d), 132.9 (d), 141.3 (d), 149.8 (d), 150.9 (d), 161.9 (s). ESI-MS m/z: $354.3\left(\mathrm{C}_{18} \mathrm{H}_{15} \mathrm{~N}_{3} \mathrm{O}_{5},[\mathrm{M}+\mathrm{H}]^{+}\right)$. Anal. Calcd for $\mathrm{C}_{18} \mathrm{H}_{15} \mathrm{~N}_{3} \mathrm{O}_{5}: \mathrm{C}$, 61.19; H, 4.28; N, 11.89; Found: C, 61.32; H, 4.33; N, 11.95\%.

$(E)-N^{\prime}-((E)-3-(4-B$ romophenyl) allylidene $)-2,3$ dihydrobenzo $[b][1,4]$ dioxine-5-carbohydrazide (B7) Brown powder, yield 79\%; mp $186-188^{\circ} \mathrm{C} . \quad{ }^{1} \mathrm{H}-\mathrm{NMR}$ $\left(300 \mathrm{MHz}, \quad \mathrm{DMSO}-d_{6}\right) \quad \delta: 4.54 \quad(4 \mathrm{H}, \mathrm{s}), 6.97-7.05 \quad(2 \mathrm{H}$, m),7.09-7.12 (1H, m), 7.40-7.48 (3H, m), 7.56-7.64 (4H, m), $10.94(1 \mathrm{H}, \mathrm{s}) .{ }^{13} \mathrm{C}-\mathrm{NMR}\left(75 \mathrm{MHz}, \mathrm{DMSO}-d_{6}\right) \delta: 61.6(\mathrm{t}), 63.3$ (t), 119.6 (d), 121.1 (d), 122.4 (d), 122.6 (d), 122.8 (d), 128.1 (d), 128.4 (d), 129.8 (d), 131.6 (d), 137.5 (d), 141.4 (d), 149.8 (d), 150.9 (d), 161.8 (s). ESI-MS m/z: $387.0 \quad\left(\mathrm{C}_{18} \mathrm{H}_{15} \mathrm{BrN}_{2} \mathrm{O}_{3}\right.$, $\left.[\mathrm{M}+\mathrm{H}]^{+}\right) ; 389.0\left([\mathrm{M}+2+\mathrm{H}]^{+}\right)$. Anal. Calcd for $\mathrm{C}_{18} \mathrm{H}_{15} \mathrm{BrN}_{2} \mathrm{O}_{3}$ : C, 55.83; H, 3.90; Br, 20.63; N, 7.23; Found: C, 55.79; H, 3.91; $\mathrm{N}, 7.33 \%$.

$(E)-N^{\prime}-((E)-3-(4-M e t h o x y p h e n y l) a l l y l i d e n e)-2,3-$ dihydrobenzo $[b][1,4]$ dioxine-5-carbohydrazide (B8) Light yellow powder, yield $81 \%$; mp $160-162^{\circ} \mathrm{C}$. ${ }^{1} \mathrm{H}-\mathrm{NMR}$ $\left(300 \mathrm{MHz}, \mathrm{DMSO}-d_{6}\right) \delta: 3.80(3 \mathrm{H}, \mathrm{s}), 4.31(4 \mathrm{H}, \mathrm{s}), 6.51-6.55$ $(2 \mathrm{H}, \mathrm{m}), 6.92-6.95(1 \mathrm{H}, \mathrm{m}), 7.05-7.10(1 \mathrm{H}, \mathrm{m}), 7.16-7.19$ $(1 \mathrm{H}, \mathrm{m}), 7.39-7.45(2 \mathrm{H}, \mathrm{m}), 7.60-7.66(3 \mathrm{H}, \mathrm{m}), 10.94(1 \mathrm{H}, \mathrm{s})$. ${ }^{13} \mathrm{C}-\mathrm{NMR}\left(75 \mathrm{MHz}, \mathrm{DMSO}-d_{6}\right) \delta: 56.2(\mathrm{q}), 61.6(\mathrm{t}), 63.3(\mathrm{t})$,
114.5 (d), 119.6 (d), 121.1 (d), 122.4 (d), 122.7 (d), 128.1 (d), 128.4 (d), 129.8 (d), 130.6 (d), 141.4 (d), 149.8 (d), 150.9 (d), 160.7 (d), 161.8 (s). ESI-MS m/z: $339.3\left(\mathrm{C}_{19} \mathrm{H}_{18} \mathrm{~N}_{2} \mathrm{O}_{4},[\mathrm{M}+\mathrm{H}]^{+}\right)$. Anal. Calcd for $\mathrm{C}_{19} \mathrm{H}_{18} \mathrm{~N}_{2} \mathrm{O}_{4}$ : C, 67.44; H, 5.36; N, 8.28; Found: C, 67.41; H, 5.32; N, 8.33\%.

(E) - $N^{\prime}-((E)-3-(4-N i t$ rophenyl) allylidene $)-2,3$ dihydrobenzo $[b][1,4]$ dioxine-5-carbohydrazide (B9) Yellow powder, yield $85 \%$; mp $210-212{ }^{\circ} \mathrm{C}$. ${ }^{1} \mathrm{H}-\mathrm{NMR}(300 \mathrm{MHz}$, DMSO- $\left.d_{6}\right) \delta: 4.36(4 \mathrm{H}, \mathrm{s}), 7.13-7.17(2 \mathrm{H}, \mathrm{m}), 7.34-7.36(2 \mathrm{H}$, m), 7.48-7.51 (2H, m), $8.10(2 \mathrm{H}, \mathrm{d}, J=5.12), 8.35(2 \mathrm{H}, \mathrm{d}$, $J=5.21), 10.92(1 \mathrm{H}, \mathrm{s}) .{ }^{13} \mathrm{C}-\mathrm{NMR}\left(75 \mathrm{MHz}, \mathrm{DMSO}-d_{6}\right) \delta: 61.6$ (t), 63.3 (t), 119.6 (d), 121.1 (d), 122.4 (d), 122.7 (d), 124.5 (d), 128.1 (d), 128.3 (d), 128.9 (d), 141.4 (d), 144.3 (d), 147.6 (d), 149.8 (d), 150.9 (d), 161.9 (s). ESI-MS m/z: $354.4\left(\mathrm{C}_{18} \mathrm{H}_{15} \mathrm{~N}_{3} \mathrm{O}_{5}\right.$, $\left.[\mathrm{M}+\mathrm{H}]^{+}\right)$. Anal. Calcd for $\mathrm{C}_{18} \mathrm{H}_{15} \mathrm{~N}_{3} \mathrm{O}_{5}: \mathrm{C}, 61.19 ; \mathrm{H}, 4.28 ; \mathrm{N}$, 11.89; Found: C, 61.12; H, 4.33; N, 11.96.

(E)- $N^{\prime}$-((E)-3-Phenylallylidene)-2,3-dihydrobenzo $[b][1,4]-$ dioxine-6-carbohydrazide (C3) Light yellow powder, yield $87 \%$; mp $172-174^{\circ} \mathrm{C}$. ${ }^{1} \mathrm{H}-\mathrm{NMR}\left(300 \mathrm{MHz}, \mathrm{DMSO}-d_{6}\right) \delta: 4.32$ (4H, s), 6.90-6.95 (2H, m), $7.22(1 \mathrm{H}, \mathrm{d}, J=8.22 \mathrm{~Hz}), 7.40-7.54$ (5H, m), 7.60-7.68 (3H, m), $11.34(1 \mathrm{H}, \mathrm{s}) .{ }^{13} \mathrm{C}-\mathrm{NMR}(75 \mathrm{MHz}$, DMSO- $\left.d_{6}\right) \delta: 61.8(\mathrm{t}), 111.5$ (d), 119.6 (d), 121.9 (d), 122.4 (d), 122.9 (d), 127.5 (d), 128.1 (d), 128.3 (d), 128.8 (d), 137.2 (d), 145.7 (d), 149.5 (d), 150.9 (d), 163.1 (s). ESI-MS m/z: 309.3 $\left(\mathrm{C}_{18} \mathrm{H}_{16} \mathrm{~N}_{2} \mathrm{O}_{3},[\mathrm{M}+\mathrm{H}]^{+}\right)$. Anal. Calcd for $\mathrm{C}_{18} \mathrm{H}_{16} \mathrm{~N}_{2} \mathrm{O}_{3}$ : C, 70.12; H, 5.23; N, 9.09; Found: C, 70.03; H, 5.21; N, 9.14\%.

(E) - $N^{\prime}$ - ( (E) - 3 - (2 - Fluorophenyl)allylidene) - 2,3 dihydrobenzo $[b][1,4]$ dioxine-6-carbohydrazide (C4) Light yellow powder, yield $68 \%$; mp $178-180^{\circ} \mathrm{C}$. ${ }^{1} \mathrm{H}-\mathrm{NMR}$ $\left(300 \mathrm{MHz}, \mathrm{DMSO}-d_{6}\right) \delta: 4.31(4 \mathrm{H}, \mathrm{s}), 6.88(1 \mathrm{H}, \mathrm{d}, J=4.77 \mathrm{~Hz})$, $7.00-7.04(2 \mathrm{H}, \mathrm{m}), 7.12(2 \mathrm{H}, \mathrm{m}), 7.36(1 \mathrm{H}, \mathrm{m}), 7.48-7.60(4 \mathrm{H}$, m), $11.05(1 \mathrm{H}, \mathrm{s}) .{ }^{13} \mathrm{C}-\mathrm{NMR}\left(75 \mathrm{MHz}, \mathrm{DMSO}-d_{6}\right) \delta: 61.6(\mathrm{t})$, 111.9 (d), 115.7 (d, $J=20.9$ C20-F coupling), 122.0 (d), 122.2 (d), 122.4 (d, J=7.7 C17-F coupling), 122.9 (d), 124.5 (d, $J=20.1$ C18-F coupling), 125.4 (d), 126.5 (d), 128.3 (d, $J=8.6$ C23-F coupling), 129.0 (d, $J=7.2$ C21-F coupling), 145.4 (d), 149.6 (d), 150.9 (d), 161.3 (d, $J=251.9$ C19-F coupling), 163.2 (s). ESI-MS m/z: $327.3\left(\mathrm{C}_{18} \mathrm{H}_{15} \mathrm{FN}_{2} \mathrm{O}_{3},[\mathrm{M}+\mathrm{H}]^{+}\right)$. Anal. Calcd for $\mathrm{C}_{18} \mathrm{H}_{15} \mathrm{FN}_{2} \mathrm{O}_{3}$ : C, 66.25; $\mathrm{H}, 4.63$; N, 8.58; Found: C, 66.27; $\mathrm{H}, 4.64 ; \mathrm{N}, 8.63 \%$.

$(E)-N^{\prime}-((E)-3-(2-M e t h o x y p h e n y l)$ allylidene $)-2,3$ dihydrobenzo $[b][1,4]$ dioxine-6-carbohydrazide (C5) Yellow powder, yield $75 \%$; mp $171-173^{\circ} \mathrm{C}$. ${ }^{1} \mathrm{H}-\mathrm{NMR}(300 \mathrm{MHz}$, DMSO- $\left.d_{6}\right) \delta: 3.82(3 \mathrm{H}, \mathrm{s}), 4.31(4 \mathrm{H}, \mathrm{s}), 6.81(1 \mathrm{H}, \mathrm{d}$, $J=8.76 \mathrm{~Hz}), 6.96-7.03(3 \mathrm{H}, \mathrm{m}), 7.20-7.25$ (2H, m), 7.48-7.53 $(2 \mathrm{H}, \mathrm{m}), 7.64(1 \mathrm{H}, \mathrm{s}), 7.71(1 \mathrm{H}, \mathrm{d}, J=8.58 \mathrm{~Hz}), 11.16(1 \mathrm{H}, \mathrm{s})$. ${ }^{13} \mathrm{C}-\mathrm{NMR}\left(75 \mathrm{MHz}, \mathrm{DMSO}-d_{6}\right) \delta: 56.9$ (q), $61.8(\mathrm{t}), 111.4(\mathrm{~d})$, 113.0 (d), 121.6 (d), 121.9 (d), 122.4 (d), 122.9 (d), 127.5 (d), 128.3 (d), 131.8 (d), 133.2 (d), 145.5 (d), 149.5 (d), 150.9 (d), 159.4 (d), 163.5 (s). ESI-MS m/z: $339.2\left(\mathrm{C}_{19} \mathrm{H}_{18} \mathrm{~N}_{2} \mathrm{O}_{4},[\mathrm{M}+\mathrm{H}]^{+}\right)$. Anal. Calcd for $\mathrm{C}_{19} \mathrm{H}_{18} \mathrm{~N}_{2} \mathrm{O}_{4}$ : C, 67.44; H, 5.36; N, 8.28; Found: C, 67.49; H, 5.37; N, 8.21\%.

$(E)-N^{\prime}-((E)-3-(2-N i t$ rophenyl)allylidene $)-2,3-$ dihydrobenzo $[b][1,4]$ dioxine-6-carbohydrazide (C6) Brown powder, yield $82 \%$; mp $191-193^{\circ} \mathrm{C} . \quad{ }^{1} \mathrm{H}-\mathrm{NMR}$ $\left(300 \mathrm{MHz}, \mathrm{DMSO}-d_{6}\right) \delta: 4.33(4 \mathrm{H}, \mathrm{s}), 6.73(1 \mathrm{H}, \mathrm{d}, J=3.09 \mathrm{~Hz})$, $7.15(1 \mathrm{H}, \mathrm{d}, J=4.76 \mathrm{~Hz}), 7.35-7.38(1 \mathrm{H}, \mathrm{m}), 7.47-7.53(2 \mathrm{H}, \mathrm{m})$, $7.63(1 \mathrm{H}, \mathrm{s}), 7.80-7.84(2 \mathrm{H}, \mathrm{m}), 8.03(1 \mathrm{H}, \mathrm{d}, J=6.93 \mathrm{~Hz}), 8.21$ $(1 \mathrm{H}, \mathrm{d}, J=7.02 \mathrm{~Hz}), 10.96(1 \mathrm{H}, \mathrm{s}) .{ }^{13} \mathrm{C}-\mathrm{NMR}(75 \mathrm{MHz}, \mathrm{DMSO}-$ $\left.d_{6}\right) \delta: 61.8(\mathrm{t}), 111.4(\mathrm{~d}), 121.9$ (d), 122.4 (d), 122.9 (d), 126.4 (d), 128.7 (d), 130.5 (d), 131.2 (d), 131.5 (d), 133.0 (d), 145.5 
(d), 146.4 (d), 149.5 (d), 150.9 (d), 163.3 (s). ESI-MS m/z: 354.2 $\left(\mathrm{C}_{18} \mathrm{H}_{15} \mathrm{~N}_{3} \mathrm{O}_{5},[\mathrm{M}+\mathrm{H}]^{+}\right)$. Anal. Calcd for $\mathrm{C}_{18} \mathrm{H}_{15} \mathrm{~N}_{3} \mathrm{O}_{5}$ : C, 61.19; H, 4.28; N, 11.89; Found: C, 61.17; H, 4.24; N, 11.97\%.

(E) - $N^{\prime}-((E)$-3 - (4 - Bromophenyl)allylidene ) - 2, 3 dihydrobenzo $[b][1,4]$ dioxine-6-carbohydrazide (C7) Brown powder, yield $69 \%$; mp $210-212{ }^{\circ} \mathrm{C}$. ${ }^{1} \mathrm{H}-\mathrm{NMR}$ $\left(300 \mathrm{MHz}, \mathrm{DMSO}-d_{6}\right) \delta: 4.32(4 \mathrm{H}, \mathrm{s}), 6.97(1 \mathrm{H}, \mathrm{d}, J=8.40 \mathrm{~Hz})$, $7.17-7.25(2 \mathrm{H}, \mathrm{m}), 7.48-7.55(4 \mathrm{H}, \mathrm{m}), 7.65(1 \mathrm{H}, \mathrm{s}), 7.70-7.74$ $(2 \mathrm{H}, \mathrm{m}), 10.93(1 \mathrm{H}, \mathrm{s}) .{ }^{13} \mathrm{C}-\mathrm{NMR}\left(75 \mathrm{MHz}, \mathrm{DMSO}-d_{6}\right) \delta: 61.6$ (t), 111.5 (d), 121.9 (d), 122.4 (d), 122.9 (d), 128.1 (d), 128.9 (d), 129.6 (d), 131.6 (d), 137.2 (d), 145.7 (d), 149.4 (d), 150.9 (d), 163.4 (s). ESI-MS m/z: $387.0\left(\mathrm{C}_{18} \mathrm{H}_{15} \mathrm{BrN}_{2} \mathrm{O}_{3},[\mathrm{M}+\mathrm{H}]^{+}\right) ; 389.0$ $\left([\mathrm{M}+2+\mathrm{H}]^{+}\right)$. Anal. Calcd for $\mathrm{C}_{18} \mathrm{H}_{15} \mathrm{BrN}_{2} \mathrm{O}_{3}$ : C, 55.83; H, 3.90; N, 7.23; Found: C, 55.71; H, 3.98; N, 7.27\%.

$(E)-N^{\prime}-((E)-3-(4-M e t h o x y p h e n y l)$ allylidene $)-2,3-$ dihydrobenzo $[b][1,4]$ dioxine-6-carbohydrazide (C8) Yellow powder, yield $80 \%$; mp $178-180^{\circ} \mathrm{C}$. ${ }^{1} \mathrm{H}-\mathrm{NMR}(300 \mathrm{MHz}$, DMSO- $\left.d_{6}\right) \delta: 3.85(3 \mathrm{H}, \mathrm{s}), 4.26(4 \mathrm{H}, \mathrm{s}), 6.80(1 \mathrm{H}, \mathrm{d}$, $J=5.42 \mathrm{~Hz}), 6.91 \quad(2 \mathrm{H}, \mathrm{d}, J=8.40 \mathrm{~Hz}), 7.26-7.29 \quad(2 \mathrm{H}, \mathrm{m})$, 7.46-7.52 (5H, m), $11.42(1 \mathrm{H}, \mathrm{s}) .{ }^{13} \mathrm{C}-\mathrm{NMR}(75 \mathrm{MHz}, \mathrm{DMSO}-$ $\left.d_{6}\right) \delta: 56.1(\mathrm{q}), 61.6(\mathrm{t}), 111.5(\mathrm{~d}), 114.1$ (d), 121.9 (d), 122.4 (d), 122.9 (d), 128.1 (d), 128.9 (d), 129.6 (d), 131.0 (d), 145.5 (d), 149.4 (d), 151.0 (d), 161.3 (d), 163.4 (s). ESI-MS m/z: 339.2 $\left(\mathrm{C}_{19} \mathrm{H}_{18} \mathrm{~N}_{2} \mathrm{O}_{4},[\mathrm{M}+\mathrm{H}]^{+}\right)$. Anal. Calcd for $\mathrm{C}_{19} \mathrm{H}_{18} \mathrm{~N}_{2} \mathrm{O}_{4}$ : C, 67.44; H, 5.36; N, 8.28; Found: C, 67.36; H, 5.29; N, 8.42\%.

$(E)-N^{\prime}-((E)-3$ - (4 - Nitrophenyl)allylidene $)-2,3$ dihydrobenzo $[b][1,4]$ dioxine-6-carbohydrazide (C9) Brown powder, yield $77 \%$; mp $211-214^{\circ} \mathrm{C} .{ }^{1} \mathrm{H}-\mathrm{NMR}$ $\left(300 \mathrm{MHz}, \mathrm{DMSO}-d_{6}\right) \delta: 4.31(4 \mathrm{H}, \mathrm{s}), 7.13-7.17(2 \mathrm{H}, \mathrm{m})$, 7.38-7.40 (2H, m), 7.50-7.56 (2H, m), $8.10(2 \mathrm{H}, \mathrm{m}), 8.26(2 \mathrm{H}$, $\mathrm{d}, J=7.68 \mathrm{~Hz}), 11.34(1 \mathrm{H}, \mathrm{s}) \cdot{ }^{13} \mathrm{C}-\mathrm{NMR}\left(75 \mathrm{MHz}, \mathrm{DMSO}-d_{6}\right)$ $\delta: 61.6$ (t), 111.5 (d), 121.9 (d), 122.4 (d), 122.9 (d), 124.6 (d), 128.1 (d), 128.4 (d), 128.9 (d), 145.5 (d), 147.3 (d), 149.4 (d), 151.0 (d), 163.4 (s). ESI-MS m/z: $354.3\left(\mathrm{C}_{18} \mathrm{H}_{15} \mathrm{~N}_{3} \mathrm{O}_{5},[\mathrm{M}+\mathrm{H}]^{+}\right)$. Anal. Calcd for $\mathrm{C}_{18} \mathrm{H}_{15} \mathrm{~N}_{3} \mathrm{O}_{5}$ : C, 61.19; H, 4.28; N, 11.89; Found: C, 61.09; H, 4.40; N, 11.95\%.

Biology: Bacterial Suppressive Assay The antibacterial activity of the synthesized compounds was tested against $E$. coli ATCC 25922, Pseudomonas aeruginosa ATCC 27853, Staphylococcus aureus ATCC 6538 and Bacillus subtilis ATCC 530 using MH medium (Mueller-Hinton medium: casein hydrolysate $17.5 \mathrm{~g}$, soluble starch $1.5 \mathrm{~g}$, beef extract $1000 \mathrm{~mL}$ ). The MIC values of the tested compounds were determined by a colorimetric method using the dye MTT A stock solution of the synthesized compound $(100 \mu \mathrm{g} / \mathrm{mL})$ in dimethyl sulfoxide (DMSO) was prepared and graded quantities of the test compounds were incorporated in specified quantity of sterilized liquid MH medium. A specified quantity of the medium containing the compound was poured into microtitration plates. Suspension of the microorganism was prepared to contain approximately $10^{5} \mathrm{cfu} / \mathrm{mL}$ and applied to microtitration plates with serially diluted compounds in DMSO to be tested and incubated at $37^{\circ} \mathrm{C}$ for $24 \mathrm{~h}$. After the MICs were visually determined on each of the microtitration plates, $50 \mu \mathrm{L}$ of phosphate buffered saline (PBS) $0.01 \mathrm{~mol} / \mathrm{L}$, pH 7.4: $\mathrm{Na}_{2} \mathrm{HPO}_{4} \cdot 12 \mathrm{H}_{2} \mathrm{O} 2.9 \mathrm{~g}, \mathrm{KH}_{2} \mathrm{PO}_{4} 0.2 \mathrm{~g}, \mathrm{NaCl} 8.0 \mathrm{~g}, \mathrm{KCl}$ $0.2 \mathrm{~g}$, distilled water $1000 \mathrm{~mL}$ ) containing $2 \mathrm{mg}$ of $\mathrm{MTT} / \mathrm{mL}$ was added to each well. Incubation was continued at room temperature for $4-5 \mathrm{~h}$. The content of each well was removed, and $100 \mu \mathrm{L}$ of isopropanol containing $5 \% 1 \mathrm{~mol} / \mathrm{L} \mathrm{HCl}$ was added to extract the dye. After $12 \mathrm{~h}$ of incubation at room temperature, the optical density (OD) was measured with a microplate reader at $550 \mathrm{~nm}$.

E. coli FabH Inhibitory Assay Native E. coli FabH protein was overexpressed in E. coli BL21 (DE3) cells using the pET30 vector and purified to homogeneity in three chromatographic steps (Q-Sepharose, MonoQ, and hydroxyapatite) at $4^{\circ} \mathrm{C}$. The selenomethionine-substituted protein was expressed in E. coli BL21 (DE3) cells and purified in a similar way. Harvested cells containing FabH were lysed by sonication in $20 \mathrm{~mm}$ Tris, $\mathrm{pH} 7.6,5 \mathrm{~mm}$ imidazole, $0.5 \mathrm{M} \mathrm{NaCl}$ and centrifuged at $20000 \mathrm{rpm}$ for $30 \mathrm{~min}$. The supernatant was applied to a Ni-NTA agarose column, washed, and eluted using a 5-500 mm imidazole gradient over 20 column volumes. Eluted protein was dialyzed against $20 \mathrm{~mm}$ Tris, $\mathrm{pH} 7.6,1 \mathrm{~mm}$ dithiothreitol (DTT), and $100 \mathrm{~mm} \mathrm{NaCl}$. Purified FabHs were concentrated up to $2 \mathrm{mg} / \mathrm{mL}$ and stored at $-80^{\circ} \mathrm{C}$ in $20 \mathrm{~mm}$ Tris, $\mathrm{pH} 7.6,100 \mathrm{~mm} \mathrm{NaCl}, 1 \mathrm{~mm}$ DTT, and $20 \%$ glycerol for enzymatic assay. In a final $20 \mu \mathrm{L}$ reaction, $20 \mathrm{~mm} \mathrm{Na}_{2} \mathrm{HPO}_{4}$, pH 7.0, $0.5 \mathrm{~mm}$ DTT, $0.25 \mathrm{~mm} \mathrm{MgCl}_{2}$, and $2.5 \mu \mathrm{M}$ holo-ACP were mixed with $1 \mathrm{~nm} \mathrm{FabH}$, and $\mathrm{H}_{2} \mathrm{O}$ was added to $15 \mu \mathrm{L}$. After $1 \mathrm{~min}$ incubation, a $2 \mu \mathrm{L}$ mixture of $25 \mu \mathrm{M}$ acetyl-CoA, $0.5 \mathrm{~mm}$ reduced nicotinamide adenine dinucleotide (NADH), and $0.5 \mathrm{~mm}$ NADPH was added for FabH reaction for $25 \mathrm{~min}$. The reaction was stopped by adding $20 \mu \mathrm{L}$ of ice-cold $50 \%$ trichloroacetic acid (TCA), incubating for $5 \mathrm{~min}$ on ice, and centrifuging to pellet the protein. The pellet was washed with $10 \%$ ice-cold TCA and resuspended with $5 \mu \mathrm{L}$ of $0.5 \mathrm{M} \mathrm{NaOH}$. The incorporation of the ${ }^{3} \mathrm{H}$ signal in the final product was read by liquid scintillation. When determining the inhibition constant $\left(\mathrm{IC}_{50}\right)$, inhibitors were added from a concentrated DMSO stock such that the final concentration of DMSO did not exceed $2 \%$.

Docking Study The three-dimensional structures of test compounds were constructed using Chem. 3D ultra 12.0 software [Chemical Structure Drawing Standard; Cambridge Soft Corporation, U.S.A. (2010)], then they were energetically minimized by using MMFF94 with 5000 iterations and minimum RMS gradient of 0.10 . The crystal structures of $E$. coli FabH (PDB code: 1 HNJ) complex were retrieved from the RCSB Protein Data Bank (http://www.rcsb.org/pdb/home/ home.do). All bound waters and ligands were eliminated from the protein and the polar hydrogen was added to the proteins.

Molecular docking of compounds C14 and D6 into the three-dimensional X-ray structure of E. coli FabH (PDB code: $1 \mathrm{HNJ}$ ) was carried out using the Discovery Stutio (version 3.1) as implemented through the graphical user interface DS-CDocker protocal. CDOCKER is an implementation of a CHARMm based molecular docking tool using a rigid receptor, including the steps in literature. ${ }^{25)}$

Acknowledgment The authors thank the support by Zhejiang Department of Education Fund Y201330227.

\section{References}

1) Wang J., Soisson S. M., Young K., Shoop W., Kodali S., Galgoci A., Painter R., Parthasarathy G., Tang Y. S., Cummings R., Ha S., Dorso K., Motyl M., Jayasuriya H., Ondeyka J., Herath K., Zhang C. W., Hernandez L., Allocco J., Basilio A., Tormo J. R., Genilloud O., Vicente F., Pelaez F., Colwell L., Lee S. H., Michael B., Felcetto T., Gill C., Silver L. L., Hermes J. D., Bartizal K., Barrett J., Schmatz D., Becker J. W., Cully D., Singh S. B., Nature (London), 
441, 358-361 (2006).

2) Wang J., Kodali S., Lee S. H., Galgoci A., Painter R., Dorso K., Racine F., Motyl M., Hernandez L., Tinney E., Colletti S. L., Herath K., Cummings R., Salazar O., Gonzalez I., Basilio A., Vicente F., Genilloud O., Pelaez F., Jayasuriya H., Young K., Cully D. F., Singh S. B., Proc. Natl. Acad. Sci. U.S.A., 104, 7612-7616 (2007).

3) Lee J. Y., Jeong K. W., Lee J. U., Kang D. I., Kim Y., Bioorg. Med. Chem., 17, 1506-1513 (2009).

4) Li Z. L., Li Q. S., Zhang H. J., Hu Y., Zhu D. D., Zhu H. L., Bioorg. Med. Chem., 19, 4413-4420 (2011).

5) Nie Z., Perretta C., Lu J., Su Y., Margosiak S., Gajiwala K. S., Cortez J., Nikulin V., Yager K. M., Appelt K., Chu S. S., J. Med. Chem., 48, 1596-1609 (2005).

6) de Souza M. V., Pais K. C., Kaiser C. R., Peralta M. A., de L Ferreira M., Lourenco M. C., Bioorg. Med. Chem., 17, 1474-1480 (2009).

7) Lv P. C., Wang K. R., Yang Y., Mao W. J., Chen J., Xiong J., Zhu H. L., Bioorg. Med. Chem. Lett., 19, 6750-6754 (2009).

8) Cheng K., Zheng Q. Z., Qian Y., Shi L., Zhao J., Zhu H. L., Bioorg. Med. Chem., 17, 7861-7871 (2009).

9) Shi L., Fang R. Q., Zhu Z. W., Yang Y., Cheng K., Zhong W. Q., Zhu H. L., Eur. J. Med. Chem., 45, 4358-4364 (2010).

10) Lee J. Y., Jeong K. W., Shin S., Lee J. U., Kim Y., Eur. J. Med. Chem., 47, 261-269 (2012).

11) Li H. Q., Luo Y., Lv P. C., Shi L., Liu C. H., Zhu H. L., Bioorg. Med. Chem. Lett., 20, 2025-2028 (2010).

12) Yang Y. S., Zhang F., Gao C., Zhang Y. B., Wang X. L., Tang J. F., Sun J., Gong H. B., Zhu H. L., Bioorg. Med. Chem. Lett., 22, 4619-4624 (2012).
13) Matos M. A. R., Sousa C. C. S., Morais V. M. F., J. Phys. Chem. A, 112, 7961-7968 (2008)

14) Pferschy-Wenzig E. M., Atanasov A. G., Malainer C., Noha S. M., Kunert O., Schuster D., Heiss E. H., Oberlies N. H., Wagner H., Bauer R., Dirsch V. M., J. Nat. Prod., 77, 842-847 (2014).

15) Takemoto T., Ikegawa S., Nomoto K., Yakugaku Zasshi, 95, 1017 1021 (1975).

16) Debenedetti S. L., Nadinic E. L., Coussio J. D., Kimpe N. D., Dupon J. F., Declercq J. P., Phytochemistry, 30, 2757-2758 (1991).

17) Tsukamoto S., Kato H., Hirota H., Fusetani N., Tetrahedron, 50, 13583-13592 (1994).

18) Harrak Y., Rosell G., Daidone G., Plescia S., Schillaci D., Pujol M. D., Bioorg. Med. Chem., 15, 4876-4890 (2007).

19) Vázquez M. T., Rosell G., Pujol M. D., Eur. J. Med. Chem., 32, 529-534 (1997)

20) Xu M.-Z., Lee W. S., Han J.-M., Oh H.-W., Park D.-S., Tian G.-R., Jeong T.-S., Park H.-Y., Bioorg. Med. Chem., 14, 7826-7834 (2006).

21) Hou Y.-P., Sun J., Pang Z.-H., Lv P.-C., Li D.-D., Yan L., Zhang H.-J., Zheng E. X., Zhao J., Zhu H.-L., Bioorg. Med. Chem., 19, 5948-5954 (2011).

22) Wang X.-L., Zhang Y.-B., Tang J.-F., Yang Y.-S., Chen R.-Q., Zhang F., Zhu H.-L., Eur. J. Med. Chem., 57, 373-382 (2012).

23) He X., Reeve A. M. E., Desai U. R., Kellogg G. E., Reynolds K. A., Antimicrob. Agents Chemother., 48, 3093-3102 (2004).

24) Qiu X. Y., Janson C. A., Smith W. W., Head M., Lonsdale J., Konstantinidis A. K., J. Mol. Biol., 307, 341-356 (2001).

25) Wu G. S., Robertson D. H., Brooks C. L. 3rd, Vieth M., J. Comput. Chem., 24, 1549-1562 (2003). 